\title{
Oral Accuracy, Field Dependent/Independent Cognitive Styles and Corrective Feedback
}

\author{
Ali Mohammadi Darabad \\ M.A graduate in TEFL \\ PO Box 13518-57195, Tehran, Iran \\ Tel: 98-912-7070-951_E-mail: Mohammadi.ali741@gmail.com
}

Received: January 17, 2013 Accepted: February 13, 2013 Published: February 18, 2013

doi:10.5296/ijele.v1i1.3273 URL: http://dx.doi.org/10.5296/ijele.v1i1.3273

\begin{abstract}
This study examined the effect of two types of corrective feedback (prompts and recasts) on oral accuracy of 150 Iranian elementary EFL participants (18-25 years old) considering their cognitive styles as being field dependent/independent (FD/FI) measured by Group Embedded Figures Test (GEFT). We used the Key English Test 2 (KET) (2003) as a placement test. Of these participants, based on the scores taken from placement test and group embedded figures test, 60 participants (30 field dependents and 30 field independents) were selected and randomly assigned into three groups (prompt, recast, and control groups) each of them containing $20 \mathrm{FD}$ and FI members. The study followed placement test, GEFT, pre-test, treatment sessions, immediate post-test, and delayed post-test design. A mixed between-within subjects analysis of variance (SPANOVA) was conducted to assess the impact of the two different interventions (prompts, recasts) on participants scores on oral accuracy, across three time periods (pre-intervention, post-intervention, three weeks follow-up). There was a statistically significant interaction between program types (corrective feedback) and the time, and also a substantial main effect for that, with both groups showing an increase on the scores of oral accuracy across three time periods. The main effect comparing the two types of intervention was statistically significant suggesting a significant difference in the effectiveness of the two teaching approaches showing the superiority of prompts over recasts in post-tests. In the meantime, the results didn't show any interaction between cognitive types and feedback conditions in terms of target language accuracy.
\end{abstract}

Keywords: Corrective feedback, Prompt, Recast, Cognitive styles, Field dependent/independent 


\section{Introduction}

Since long, the effects of corrective feedback (CF) on second or foreign language learning have been under considerable attentions and studies. These studies have been conducted in the forms of descriptive and experimental researches trying to examine a wide range of variables. In the last 10 years or so, many studies have examined the effects of CF on second language (L2) learning. There is plethora of these descriptive and experimental studies that attempted to examine a wide range of variables (e.g., type and amount of feedback, mode of feedback, learners' proficiency levels, and attitudes toward feedback). One of the reasons for this increased interest in $\mathrm{CF}$ is related to the observation that although L2 learners in communicative classrooms attain relatively high levels of comprehension ability and, to some extent, fluency in oral production, they continue to experience difficulties with accuracy, particularly in terms of morphology and syntax (Lightbown, Halter, White, \& Horst, 2002; Lightbown\&Spada, 1990, 1994). According to some studies (e.g., Doughty \& Williams, 1998; Long \& Robinson, 1998), the reason for being grammatically inaccurate can be attributed to the insufficiency of comprehensible input and exclusively meaning-based instruction.

Despite suspicions cast by Truscott (1996), CF is widely considered effective in promoting noticing and is thus helpful to L2 learning (Bitchener, Young, \& Cameron, 2005; Mackey \& Philp, 1998; Sheen, 2007). An increasing amount of research has been conducted, in both laboratory and classroom contexts, regarding the type of evidence CF provides (Egi, 2007; Leeman, 2003), the effectiveness of different types of CF (Ammar \& Spada, 2006; Ellis, Loewen, \& Erlam, 2006; Lyster, 2004; Lyster \& Izquierdo, 2009; Sheen, 2007), and also the typology of CF (Ellis, 2009). Until now, the efficacy of different types of CF on various types of grammatical features, as well as the cognitive mechanisms that these different techniques invoke, remain to be examined (Ellis, 2007). Most studies that compare different CF techniques have targeted rule-based grammatical features (e.g., Ammar \& Spada, 2006; Ellis et al., 2006; Lyster, 2004; Sheen, 2007).

Some researchers tend to differentiate feedback in terms of how explicit or implicit it is. Implicit types of feedback often take the form of recasts (Long \& Robinson, 1998). However, this dichotomous classification of feedback can be problematic (Egi, 2007). Research shows that recasts can also be quite explicit (Ellis \& Sheen, 2006; Sheen, 2006), depending on the context (e.g., Sheen, 2004) as well as the characteristics of the recasts (e.g., linguistic targets, length, and number of changes). Similarly, explicit types of feedback can also take a variety of forms. For some researchers, explicit feedback involves the indication that an error has been made (e.g., Carroll \& Swain, 1993); for others, it also includes metalinguistic information (Ellis et al., 2006), the correct form (Lyster \& Ranta, 1997), or both (Sheen, 2007).

As far as language learning is concerned, different theories have been offered by many scholars in this field so far. Looking through these theories we can find Gagne's types of learning, transfer processes, aptitude and intelligence models, personality factors, individual differences, and the like. These theories attempt to describe the universal traits of human in language learning. In addition, how people perceive, filter, store and recall the information 
are the issues that have been globally under investigation. Such processes do not account for the plethora of differences across individuals in the way they learn, or the differences within any one individual. Styles and strategies in second language learning are the matter of concern as the two important factors related to human language learning and they are considered to be different in individuals. To make a distinction among individuals based on their styles they can be spotted by being field dependent or field independent, ambiguity tolerance, reflectivity or impulsivity, visual and auditory styles. To be more specific here we focus on one dimension of being field dependent or field independent.

Each student learns in a different way and individual differences in learning have been corroborated in many studies. It has been argued that students learn in different ways, thus, instruction should be designed in such a way that it can accommodate different learning styles (Raven et al., 1993).

In addition to individual differences in terms of being field dependent or field independent, the instructional options of teachers also play a crucial role in developing language proficiency in general. One of the most significant of such options is corrective feedback $(\mathrm{CF})$.

Considering the fact that grammatical instruction has predominantly been the mainstream in English education in Iran and it also plays an important role in accuracy, it was assumed important to investigate the learners' accuracy under the instruction of communicative based lessons. In this attempt, we attempt to examine the effect of using prompts and recasts on the target language grammatical accuracy (i.e., simple past tense) in our context and then inspect the effect across field dependent and field independent learners to explore the probable moderating effect of these constructs on two corrective feedback techniques (i.e., prompts and recasts) in leading to grammatical accuracy of Iranian foreign language learners.

\section{Literature Review}

The term cognitive style refers to "variations among individuals in the preferred way of perceiving, organizing, or recalling information and experience" (Stansfield \& Hansen, 1983, p. 32). Azizi et al. (2005) refer to cognitive styles as stable attitudes, preferences or habitual strategies determining a person's typical modes of perceiving, remembering, thinking, and problem solving. Witkin, Oltman, Raskin, and Karp (1971) also define cognitive style as "self-consistent modes of functioning, which individuals show in their perceptual and intellectual activities" (p. 3). Among the various identified cognitive styles, cognitive style of field-dependence/independence has been suggested potentially more significant for second language acquisition (Larsen Freeman \& Long, 1991).

Field dependent (FD) and Field independent (FI) are the concepts developed by Witkin et al. (1977) to differentiate two distinct cognitive styles. These concepts are also referred to dimensions as a global versus an articulated style that reflected the degree to which an individual's processing of information is affected by the contextual field (Summerville, 1999). Mayer (2001) states that varying information processing skills such as selective attention, short term memory encoding, and long term recall at which FI individuals are more accurate and efficient are more likely the reasons that FI and FD learners can be differentiated. 
In language learning, the learners have to understand language items in their context and to extract them and use them in new contexts (Stern, 1983). For instance, the learner may encounter situations in which $\mathrm{s} / \mathrm{he}$ has to understand the meaning of an ambiguous sentence or to understand the meaning of a word in its context and use it in other contexts. S/he may be exposed to ill-structured sentences in the process of language learning. In such circumstances, the field in/dependent cognitive style will bear influences on language learning.

There are a considerable number of studies that have investigated the relationship between field dependence/independence and L2 Learning. Brown (1993) believes in a close relationship between field-dependence/independence cognitive style and L2 learning. In his view, "field independence is closely related to classroom learning that involves analysis, attention to details, and mastering of exercises, drills and other focused activities" while "primarily field dependent persons will, by virtue of their empathy, social out-reach and perception of other people, be successful in learning the communicative aspects of second language" (p. 106-7).

Navigating and organizing information, prioritizing content, and developing metacognitive strategies in computer based instruction are some skills that were significantly affected by the level of field independency (Oh \& Lim, 2005). On the other hand, in activities such as reorganizing and reproducing information, recognizing salient cues, and structuring information in computer based instruction than in classroom environments, FD learners tend to be less successful.

Lourdusamy (1994) indicates that based on the researches conducted in the field of cognitive strategies, individuals' ways of information seeking and information processing are different. Witkin et al. (1971) acknowledged that An FI person tends to perceive surroundings analytically, separating objects discretely from their backgrounds, while an FD person tends to perceive things in a relatively global fashion, being influenced by a prevailing field or context. Field independence is correlated with more language success especially second language learning (Alptekin \& Atakan, 1990; Chapelle \& Abraham, 1990; Chapelle \& Green, 1992). In fact, researchers show that both field dependent and field independent styles may enhance second language learning (Tianjero \& Paramo, 1998).

As Truell (2001) and Wang et al. (2001) endorsed, by investigating the researches in this domain we can find some other studies that didn't find any significant difference in students' learning outcomes based on their levels of field independency. They state that there is no correlation between cognitive styles and their performance in classroom or computer based instruction.

As it was said earlier, in addition to individual differences in terms of being field dependent or field independent, the instructional options of teachers also play a crucial role in developing language proficiency in general. One of the most significant of such options is corrective feedback $(\mathrm{CF})$.

The literature on focus on form has witnessed an increase in the number of studies that have examined the effect of corrective feedback (CF) on second language (L2) learning. Both 
descriptive and experimental research examining wide range of variables (e.g., type and amount of feedback, mode of feedback, learners' proficiency levels, and attitudes toward feedback) were included in these studies. One of the reasons for this increased interest in CF appears to be related to the observation that despite the fact that L2 learners in communicative classrooms attain relatively high levels of comprehension ability and, to some extent, fluency in oral production, they continue to have trouble with accuracy, particularly in terms of morphology and syntax (Lightbown, Halter, White, \& Horst, 2002; Lightbown \& Spada, 1990, 1994; Schmidt, 1990).

The increasing number of SLA studies also shows that CF plays a role in L2 learners' interlanguage development. Two recent meta-analysis studies provide helpful findings for future studies in this vein: Mackey and Goo (2007) conducted a meta-analysis of 28 interaction studies (including 20 oral CF studies), and Russell and Spada (2006) performed a meta-analysis of 15 CF studies (including 10 oral CF studies). Russell and Spada found that CF is facilitative of L2 development; they identified a very large effect size of 1.16. Similarly, Mackey and Goo discovered that providing CF in L2 interaction has a medium effect size of .71 in immediate post-tests and a large effect size of 1.09 in delayed post-tests. These results support the consensus that focus on form through CF is beneficial. Russell and Spada concluded, however, that "the wide range of variables examined in CF research is spread rather thin; more work is needed to consolidate efforts and focus on those CF variables that appear to be particularly fruitful for future investigation" (p. 156).

Prompts and recasts can be seen as complementary moves with different purposes for different learners in different discourse contexts. Teachers can use one or the other in accordance with their students' language abilities and content knowledge, without abandoning one at the expense of the other (Lyster, 2002). Recasts are ideal for facilitating the delivery of complex subject matter because they provide supportive, scaffolding help, which serves to move lessons ahead when the target forms in question are beyond the students' current abilities. At the same time, recasts serve as exemplars of positive evidence (Braidi, 2002; Leeman, 2003) and, as such, can be expected to facilitate the encoding of new target representations when they occur in appropriate discourse contexts. Prompts, on the other hand, in their overt aim to elicit modified output without providing any exemplar of positive evidence, serve to improve control over already internalized forms by assisting learners in the transition of declarative to procedural knowledge (de Bot, 1996; Lyster, 2004). Recasts and prompts thus elicit different types of learner responses-identified in classroom studies as different types of learner uptake and repair.

Recasts and prompts differ not only in terms of whether the target forms are given but also in the types of evidence provided. Nicholas, Lightbown, and Spada (2001) argued that recasts afford learners with positive evidence, but whether negative evidence is also provided is less clear. Other researchers (e.g., Egi, 2007; Ellis \& Sheen, 2006) believe that whether recasts provide positive evidence, negative evidence, or both largely depends on learners' perceptions, which, in turn, determine the effectiveness of recasts. It has been argued that by providing positive evidence in classroom input, recasts may help learners establish new knowledge. Prompts, in contrast, aim to provide negative evidence because they signal that 
the learners' utterance is problematic. The self-repair process is claimed to help learners to reanalyze what has already been learned (at some level) and to restructure their interlanguage (Lyster, 2002). According to de Bot (1996), learners benefit more from being pushed to "make the right connection on one's own than from hearing the correct structures in the input" (as cited in Y. Yang \& R. Lyster, 2010, p. 238). Furthermore, prompts may help learners to gain greater control over already acquired forms and to access these forms more quickly.

Prompts range from implicit to explicit but are distinguishable from recasts and explicit correction in terms of what Ortega (2009) called demand, i.e., "the degree of conversational urgency exerted upon interlocutors to react to the negative feedback" (as cited in R. Lyster \& K. Saito, 2010, p. 268). Prompts are not necessarily explicit in terms of the linguistic information they provide but might be considered explicit in terms of their illocutionary force. In other words, by prompting, a teacher provides cues for learners to draw on their own resources to self-repair, whereas by providing explicit correction or recasting, a teacher both initiates and completes a repair within a single move.

With respect to prompts, i.e., CF techniques that push learners to self-correct, Ammar (2008) investigated the effectiveness of prompts and recasts. She concluded that prompts might be more effective than recasts in that prompts cause lower-level learners to develop morpho-syntactic features. However, she acknowledged that the effectiveness of prompts lied in the easy structure, i.e., possessive determiners, and that the research investigating the effects of prompts and recasts on acquiring structures that are more complex is needed.

Lyster (2004) compared the effects of recasts and prompts after form-focused instruction (henceforth, FFI) and indicated that the FFI-prompt group significantly outperformed the group receiving recasts or the group without feedbacks in written tasks, whereas, in oral tasks, all three treatment groups performed similarly, regardless of feedback condition. He suggested that prompts allow immersion teachers to "push" their students to be more accurate in their output.

As a challenge to these advantages of prompts, Long (2006) argued that acquisition of new knowledge is the major goal, not 'automatizing' the retrieval of existing knowledge. Thus, prompts, withholding correct target forms, can only help if the learner already knows the correct target items. For the rest who do not already know the correct forms, prompts that require learners to try again immediately, only lead them to feel much more embarrassed showing their lack of knowledge publicly again.

In sum, it is obvious that using metalinguistic explanations as a CF interferes the flow of communicative interaction and treats language as an object, with focusing on the forms. As for the effects of recasts and prompts, unlike recasts, prompts do not provide the correct target forms, instead, merely demand learners to produce their own output using the already existing knowledge.

Relying on the brief review of the literature based on cognitive styles of language learning in terms of field dependent and field independent, and corrective feedback in terms of recasts 
and prompts, in this study the primary focus was on the probable relationship between field dependency and field independency and corrective feedback, i.e., prompts and recasts; through conducting the study, we were to see if the FD/FI would moderate the effect of prompts and recasts on target language grammatical accuracy.

\section{Methodology}

\subsection{Participants}

The initial participants of this study were 150 Iranian EFL learners (18-25 years old) of English at elementary level from different language institutes in Ardabil (an Iranian northwest city).

Of these participants, based on the scores taken from Placement Test and Group Embedded Figures Test (GEFT), 78 learners were selected. Half of them were field dependent (FD) and the other half were field independent (FI). The participants were randomly assigned into two experimental groups (recast and prompt) and one control group. Each group had 13 FD and 13 FI learners (the steps taken for determining homogeneity and field-in/dependency are discussed in subsequent sections).

All the participants attended the placement test, GEFT, and the pre-test. However, 18 out of 78 participants either didn't take part in the immediate post-test or were reluctant to attend the delayed post-test. Therefore, they were excluded from further analysis and the data obtained from 60 participants were taken for analysis.

\subsection{Materials}

In this study, Key English Test 2 (KET) (2003) was used for homogenizing the classroom participants. The Cambridge Key English Test (KET) is the first level of Cambridge exams in English for Speakers of Other Languages (ESOL). KET recognizes the ability to cope with everyday written and spoken communications at a basic level.

In order to determine the field-dependence or independence of learners, various tests have been developed by researchers but the version most widely used in second language acquisition is the Group Embedded Figures Test (GEFT) developed by Witkin et al. (1971). This test contains three sections and in each section, some simple forms have been hidden in more complex geometric forms. The subject's task is to locate these simple forms. The first section is used essentially for practice and the time limit for second and third sections is five minutes for each. The score is determined by the number of correct simple forms identified in the second and third section of the test.

The course book Interchange 1 Third Edition by Jack C. Richards, 2009 is used as the learners' course book in the target institute.

Elementary Stories for Reproduction by L. A. Hill, 2001 is used as a graded series of books containing short anecdotes for oral retelling.

\subsection{Procedure}

The study followed placement test administration, GEFT administration, pre-test, treatment 
sessions, immediate post-test, and delayed post-test design. The whole study was completed in 20 sessions.

\subsubsection{Placement Test}

The first two weeks of the study was completely devoted to the placement test administration in which the participants took part in written and oral parts on the test. The time allotted for the listening (20 items), reading (20 items), and language use (30 items), was 50 minutes. The placement conversation was a 10-minute, face-to-face interaction with individual students. The written test was conducted with whole class attending at once but the oral test was administered individually. The total time allotted for each individual placement was 60 minutes. We conducted the placement test and the host institutes confirmed the final placement of the participants.

\subsubsection{Determining Field Dependency and Field Independency}

After conducting the placement test the participants attended theGroup Embedded Figures Test (GEFT) developed by Witkin et al.(1971).Subjects who score above the group mean are considered to be field independent learners while subjects scoring below the group mean are considered to be fielddependent. The GEFT is considered a standardized instrument and has been tested for validity and reliability (Within, Oltman, Raskin,\& Karp, 1971).

\subsubsection{The Pre-test}

After teaching the target structural feature, i.e., simple past tense, which is one of the features in the learners' course book, the participants were given a short story chosen from Elementary Stories for Reproduction. They had five minutes to read the story and another five minutes to retell the story. Their voices were recorded and transcribed by the researcher for further analysis.

\subsubsection{Treatment Sessions}

In the third and fourth sessions, all the learners participated in a controlled practice of reading a short story in groups of three or four and then individual learners were asked to retell the story in turn. To do so, students were divided in groups of three and a copy of the selected short story was given to each member of the groups. They were asked to silently read the stories in 5 minutes and then retell the story to each other. The instructor provided the necessary explanations and clarified the problematic words whenever needed. After working on the stories for 10 minutes, one of the members of each group was randomly chosen to retell the story to the class. Prompts and recasts were applied as the CF techniques on the learners' erroneous utterance with whole class attending. In the fifth session, all the learners took part in a semi-controlled practice to make sure that all the individuals were familiar with process of presenting the story in turn. It is worth mentioning that recasts and prompts were provided on past tense errors to individual students with the whole class attending in experimental groups in every session. The control group didn't get the treatments. 


\subsubsection{The Immediate Post-test}

In the sixth session, all the participants took part in the immediate post-test of the study. In this phase, the individual learners were given some unseen short stories and were asked to choose one of the stories randomly. They were asked to silently read the story in five minutes and retell it. Then, their voices were recorded. The stories were cautiously selected and it was made sure that most of the difficult words in the stories had been taught during treatment sessions. It was done to minimize the problem of vocabulary load in checking the learners' structure use.

\subsubsection{The Delayed Post-test}

After an interval of three weeks, the participants attended the delayed post-test of the study and the results were recorded for further analysis. The procedure used in this phase was the same but the stories were different. We exchanged the short stories between the experimental and control groups. Delayed post-test was administered to check the probable effect of time on learning. To control for the test-retest effect, three different sets of short stories were used for each testing session, i.e., the pre-test, the immediate post-test, and the delayed post-test.

The obtained results from the pre-test, the immediate post-test, and the delayed post-test were plugged into the SPSS version 15, two-way ANOVA (mixed between-within subject analysis) for analysis.

\section{Results}

To check whether the different feedback conditions, cognitive styles, and the interaction of them significantly contributed to the accuracy scores, a mixed between-within subject analysis known as split-plot ANOVA (SPANOVA) was run on the tests, the results of which appear in the following tables.

Tables 1, 2, and 3 provide the descriptive statistics for the three groups in three different time periods presenting the groups (prompt, recast, control), cognitive styles (field-in/dependents), mean $(\mathrm{M})$, standard deviation (SD), and number $(\mathrm{N})$ of the participants.

Table 1. Descriptive statistics for the pre-test

\begin{tabular}{llccc}
\hline Group & Cognitive & $\mathrm{M}$ & $\mathrm{SD}$ & $\mathrm{N}$ \\
\hline prompt & Field dependent & 45.1200 & 13.04972 & 10 \\
& Field independent & 47.6700 & 10.82908 & 10 \\
& Total & 46.3950 & 11.74418 & 20 \\
recast & Field dependent & 46.3300 & 7.72443 & 10 \\
& Field independent & 54.4500 & 9.22102 & 10 \\
& Total & 50.3900 & 9.26771 & 20 \\
& Field dependent & 53.8700 & 14.24493 & 10 \\
control & Field independent & 46.5200 & 8.96311 & 10 \\
& Total & 50.1950 & 12.18154 & 20 \\
& Field dependent & 48.4400 & 12.24113 & 30 \\
Total & Field independent & 49.5467 & 10.01887 & 30 \\
& Total & 48.9933 & 11.10416 & 60 \\
\hline
\end{tabular}


Table 1 shows a little difference between the means and the standard deviations among the three groups of the study in the pre-test: prompts $(M=46.39, S D=11.74, N=20)$, recasts $(M=50.39, S D=9.26, N=20)$, control $(M=50.19, S D=12.18, N=20)$. It also shows the same statistical features for all of the participants in the three groups: total groups $(M=48.99$, $S D=11.10, N=60)$. This table also provides the statistical features of mean and standard deviation for both field dependent (FD) and field independent (FI) participants in each group: prompt group FD participants $(M=45.12, S D=13.04, N=10)$, prompt FI participants $(M=47.67$, $S D=10.82, N=10)$; recast group FD participants $(M=46.33, S D=7.72, N=10)$, recast group FI participants $(M=54.45, S D=9.22, N=10)$; control group FD participants $(M=53.87, S D=14.24$, $N=10)$, control group FI participants $(M=46.52, S D=8.96, N=10)$; total group FD participants $(M=48.44, S D=12.24, N=30)$, total group FI participants $(M=49.54, S D=10.01, N=30)$.

Table 2. Descriptive statistics for the immediate post-test

\begin{tabular}{llccc}
\hline Group & Cognitive & $\mathrm{M}$ & $\mathrm{SD}$ & $\mathrm{N}$ \\
\hline prompt & Field dependent & 79.1500 & 6.39449 & 10 \\
& Field independent & 79.1300 & 6.27235 & 10 \\
& Total & 79.1400 & 6.16479 & 20 \\
recast & Field dependent & 66.1900 & 3.60538 & 10 \\
& Field independent & 68.8900 & 5.60941 & 10 \\
& Total & 67.5400 & 4.79379 & 20 \\
control & Field dependent & 54.6900 & 7.33037 & 10 \\
& Field independent & 56.8000 & 6.98379 & 10 \\
& Total & 55.7450 & 7.05180 & 20 \\
Total & Field dependent & 66.6767 & 11.69087 & 30 \\
& Field independent & 68.2733 & 11.10309 & 30 \\
& Total & 67.4750 & 11.33237 & 60 \\
\hline
\end{tabular}

In Table 2 the descriptive statistical features for the three groups of the study in the immediate post-test are presented as follows: prompt group $(M=79.14, S D=6.16, N=20)$, recast group $(M=67.54, S D=4.79, \quad N=20)$, control group $(M=55.74, S D=7.05, N=20)$, total groups $(M=67.47, S D=11.33, N=60)$. In addition, the statistical features for FD and FI participants in the three groups are presented: prompt group FD participants $(M=79.15, S D=6.39, N=10)$, prompt FI participants $(M=79.13, S D=6.27, N=10)$; recast group FD participants $(M=66.19$, $S D=3.60, N=10)$, recast group FI participants $(M=68.89, S D=5.60, N=10)$; control group FD participants $(M=54.69, S D=7.33, N=10)$, control group FI participants $(M=56.80, S D=6.98$, $N=10)$; total group FD participants $(M=66.67, S D=11.69, N=30)$, total group FI participants $(M=68.27, S D=11.10, N=30)$. 


\section{Macrothink}

Table 3.Descriptive statistics for the delayed post-test

\begin{tabular}{llccc}
\hline Group & Cognitive & $\mathrm{M}$ & $\mathrm{SD}$ & $\mathrm{N}$ \\
\hline prompt & Field dependent & 73.7100 & 9.40573 & 10 \\
& Field independent & 77.6500 & 9.16057 & 10 \\
& Total & 75.6800 & 9.25962 & 20 \\
recast & Field dependent & 67.8600 & 5.44349 & 10 \\
& Field independent & 68.3500 & 5.27326 & 10 \\
& Total & 68.1050 & 5.22217 & 20 \\
control & Field dependent & 57.9600 & 11.40002 & 10 \\
& Field independent & 58.9800 & 13.51894 & 10 \\
& Total & 58.4700 & 12.18217 & 20 \\
Total & Field dependent & 66.5100 & 10.98618 & 30 \\
& Field independent & 68.3267 & 12.30814 & 30 \\
& Total & 67.4183 & 11.60283 & 60 \\
\hline
\end{tabular}

The descriptive statistical features in delayed post-test are provided for all the groups of the study in Table 3 as follows: prompt group $(M=75.68, S D=9.25, N=20)$, recast group $(M=68.10$, $S D=5.22, N=20)$, control group $(M=58.47, S D=12.18, N=20)$, total groups $(M=67.41$, $S D=11.60, N=60)$. In addition, the statistical features for FD and FI participants in the three groups are presented: prompt group FD participants $(M=73.71, S D=9.40, N=10)$, prompt FI participants $(M=77.65, S D=9.16, N=10)$; recast group FD participants $(M=67.86, S D=5.44$, $N=10)$, recast group FI participants $(M=68.35, S D=5.27, N=10)$; control group FD participants $(M=57.96, S D=11.40, N=10)$, control group FI participants $(M=58.98, S D=13.51$, $N=10)$; total group FD participants $(M=66.51, S D=10.98, N=30)$, total group FI participants $(M=68.32, S D=11.60, N=30)$.

Table 4. Test of within-subjects effects

\begin{tabular}{|c|c|c|c|c|c|c|c|}
\hline Effect & & Value & $\mathrm{F}$ & Hypothesis df & Error df & Sig. & $\left(\eta_{p}^{2}\right)$ \\
\hline Time & $W L^{k+1}$ & .252 & 78.497 & 2.000 & 53.000 & .000 & .748 \\
\hline Time* group & $W L^{4+}$ & .475 & 11.933 & 4.000 & 106.000 & .000 & .310 \\
\hline Time*Cognitive style & $W L^{*+4}$ & .999 & .020 & 2.000 & 53.000 & .980 & .001 \\
\hline Time* group $*$ Cognitive & $W L^{k+s}$ & .896 & 1.502 & 4.000 & 106.000 & .207 & .054 \\
\hline
\end{tabular}

**Wilks' Lambda

Table 4 shows the statistical results for the within-subject effects. As it is shown in the table, the effect of time was statistically significant $(p<0005)$ in leading the feedback conditions to be effective during the treatment sessions: Wilk's Lambda $=.25, F(2,53)=78.49, p<.0005$, partial eta squared $=.74$ with both groups showing an increase on the scores of oral accuracy of the participants across three time periods. The interaction effect of time and group is also statistically significant at the alpha level of .05: Wilk's Lambda $=.47, F(4,106)=11.93$, $p<0005$, partial eta squared .31. The interaction effect of time and cognitive style (field 
dependent and field independent participants) was not statistically significant at the alpha level of .05: Wilk's Lambda $=.99, F(2,53)=.02, p>.05$, partial eta squared $=.001$ suggesting that cognitive styles (field dependent and field independent participants) does not have a moderating effect in leading to grammatical accuracy of the participants in this study. The within-subjects effects table also does not show a statistically significant effect for the interaction among time, group, and cognitive styles in this study: Wilk's Lambda $=.89, F$ (4, 106) $=1.50, p>.05$, partial eta squared $=.05$.

Table 5. Levene's test of equality of error variances

\begin{tabular}{ccccc}
\hline Time & $\mathrm{F}$ & $\mathrm{df} 1$ & $\mathrm{df} 2$ & Sig. \\
\hline 1 & .875 & 5 & 54 & .504 \\
2 & 1.506 & 5 & 54 & .203 \\
3 & 1.604 & 5 & 54 & .175 \\
\hline
\end{tabular}

To check the assumption of homogeneity of variances we refer to the Levene's test of equality of error variances (Table 5). We want the Sig. value to be non-significant (bigger than .05). In this case the value for each variable is greater than $.05(.50, .20$, and .17); therefore, we have not violated the assumption of homogeneity of variances.

Table 6. Tests of between-subjects effects

\begin{tabular}{llllllll}
\hline Source & $\begin{array}{l}\text { Type III sum } \\
\text { of squares }\end{array}$ & df & Mean Square & F & Sig. & $\left(\boldsymbol{\eta}_{\boldsymbol{p}}^{2}\right)$ \\
\hline Intercept & 676286.124 & 1 & 676286.124 & 5815.847 & .000 & .991 \\
Group & 4561.513 & 2 & 2280.757 & 19.614 & .000 & .421 \\
Error & 6279.301 & 54 & 116.283 & & & \\
\hline
\end{tabular}

Table 6 shows the between-subjects effects results for the groups (prompt and recast groups) of this study. We can see that there is a statistically significant effect for the groups across the three time periods at alpha level of $.05(\mathrm{p}<.05)$. Therefore, we conclude that the main effect for group is significant. There was a significant difference the oral accuracy scores for the two groups (those who received prompts and those who received recasts). The effect size of the between-subject effect is also given in this table. The partial eta squared value for group in this case is .42 which shows a very large effect size. Comparing the means of prompt and recast groups reveals that both experimental groups outperformed the control group and the performance of prompt group was better than recast group in immediate and delayed post-tests (see Table 7).

In brief, a mixed between-within subjects analysis of variance was conducted to assess the impact of the two different interventions (prompts, recasts) on participants scores on oral accuracy, across three time periods (pre-intervention, post-intervention, three weeks follow-up). There was a statistically significant interaction between program types (corrective 
feedback techniques) and time, Wilk's Lambda $=.48, F(4,106)=11.93, p=.000$, partial eta squared $=.31$. There was substantial main effect for time, Wilk's Lambda $=.25, F(2,53)=$ $78.49, p<.0005$, partial eta squared $=.74$ with both groups showing an increase on the scores of oral accuracy of the participants across three time periods (see Table 7). The main effect comparing the two types of intervention was statistically significant, $F(5,54)=19.61, p$ $=.000$, partial eta squared $=.421$, suggesting a significant difference in the effectiveness of the two teaching approaches.

Table 7. The oral accuracy scores for prompt, recast, and control groups across three time periods

\begin{tabular}{lccccccccc}
\hline Groups & \multicolumn{3}{c}{ Prompts } & \multicolumn{3}{c}{ Recasts } & \multicolumn{3}{c}{ Control } \\
\hline Time period & $\mathrm{N}$ & $\mathrm{M}$ & $\mathrm{SD}$ & $\mathrm{N}$ & $\mathrm{M}$ & $\mathrm{SD}$ & $\mathrm{N}$ & $\mathrm{M}$ & $\mathrm{SD}$ \\
Pre-intervention & 20 & 46.39 & 11.74 & 20 & 50.39 & 9.26 & 20 & 50.19 & 12.18 \\
Post-intervention & 20 & 79.14 & 6.16 & 20 & 67.54 & 4.79 & 20 & 55.74 & 7.05 \\
Three weeks follow-up & 20 & 75.68 & 9.25 & 20 & 68.10 & 5.22 & 20 & 58.47 & 12.18 \\
\hline
\end{tabular}

\section{Discussion and Conclusion}

As outlined previously, there were two aims of conducting this study. We attempted to examine the effect of using prompts and recasts on the target language grammatical accuracy of Iranian foreign language learners and at the same time the superiority of one to the other, and then inspect the effect across field dependent and field independent learners to explore a probable moderating effect of these constructs on two corrective feedback techniques(i.e., prompts and recasts) in leading to grammatical accuracy in our context. The results lent some support to the first alternative, but no evidence was found to support the second alternative.

In line with the first alternative, significant effect of prompts and recast was seen across three time periods of testing the participants' oral accuracy; both prompt and recast groups showed an increasing effect in their oral accuracy scores comparing with their counterparts in control group. This result is consistent with prior studies that indicated that CF in the form of prompts and recasts are facilitative of L2 development and that its impact is sustained until delayed post-test (Cesnik, 2001; Lyster \& Saito, 2010; Mackey \& Goo, 2007; Russell \& Spada, 2006). This study further showed that prompts were superior to recasts. It can be seen that some classroom studies conducted in a range of instructional settings have demonstrated that prompts lead to greater gains in accuracy than do recasts (Ammar \& Spada, 2006; Ellis, 2007; Ellis et al., 2006; Havranek \& Cesnik, 2001; Loewen \& Philp, 2006; Lyster, 2004). Moreover, it is in line with Yang and Lyster's (2010) study in which they concluded that learners benefits more from prompts than from recasts.

In the meantime, it was aimed to find out whether there is a relationship between cognitive types, i.e., field dependency and field independency, and learners' responses to recasts and prompts in leading to the target language grammatical accuracy. The results revealed that in prompt group the field dependent and field independent participants scored not that much mean difference in the immediate and delayed post-tests and the difference among them was not 
statistically significant. Additionally, in recast group, the results didn't show any statistically significant difference between field dependent and field independent participants in the post-tests. It seems that cognitive types didn't have a moderating role in this regard. Therefore, this study didn't find any interaction between cognitive types and feedback conditions in terms of target language accuracy in our context. In another study conducted by Altun and Cakan (2006) on the effect of cognitive styles and attitude toward computer in web-based instruction they couldn't find any significant relationship between FI/FD participants and their academic achievement either. However, there have been a considerable number of studies that investigated the relationship between FI/FD and language learning and reported a close relationship between them in the presence of other factors, e.g., classroom learning that involves focused activities like drills, attention to details, and mastering of exercises (Brown, 1994), navigating and organizing information, prioritizing content, and developing metacognitive strategies in computer-based instruction (Oh \& Lim, 2005). Based on the previous studies (e.g., Brown, 1994; Musser, 1998; Town, 2003), the potential sources of difference between the performance of field dependents and field independents may be attributable to the difference between the two groups in the kind of reasoning, the restructuring ability, the use of strategies in processing information, and memory retrieval. Despite the excessive studies on the role of cognitive styles in language teaching contexts, we are still witnessing some controversial results in this domain. To find a more comprehensive conclusion in the effect of cognitive styles on different aspects of language learning and teaching the importance of conducting a meta-analysis is felt in order to disperse the fogs over the issues.

\subsection{Limitations of the Study}

As it is true for most of the empirical studies, this research faced some limitations in the course of conduction. The main limitation of the study may concern the sample gender. The present research was conducted just with male learners, and sex could be an interfering factor. On the other hand, this study targeted just English simple past tense as its main language component being studied and the results might not hold true for other forms and further research might explore learners' noticing of other forms.

\section{References}

Alptekin, C., \& Atakan, S. (1990). Field dependence-independence and hemisphericity as variables in L2 achievement. Second Language Research, 6, 135-149. http://dx.doi.org/10.1177/026765839000600203

Altun, A., \& Cakan, M. (2006).Undergraduate students' academic achievement, field dependent/independent cognitive styles and attitude toward computers. Educational Technology and Society, 9(1), 289-297.

Ammar, A. (2008). Prompts and recasts: Differential effects on second language morphosyntax. Language Teaching Research, 12(2), 183-210. http://dx.doi.org/10.1177/1362168807086287

Ammar, A., \& Spada, N. (2006). One size fits all? Prompts, recasts, and L2 learning. Studies in 
Second Language Acquisition, 28, 543-574. http://dx.doi.org/10.1017/S0272263106060268

Azizi, Y., Asmah, S., Zurihanmi, Z., \& Fawziah, Y. (2005). AplikasiKognitifDalamPendidikan. [Cognitive application in education]. Pahang: PTS Professional, 80-91.

Bitchener, J., Young, S., \& Cameron, D. (2005). The effect of different kinds of corrective feedback on ESL student writing. Journal of Second Language Writing, 14(3), 191-205. http://dx.doi.org/10.1016/j.jslw.2005.08.001

Braidi, S. M. (2002). Reexamining the role of recasts in native-speaker/nonnative-speaker interactions. Language Learning, 52, 1-42. http://dx.doi.org/10.1111/1467-9922.00176

Brown, H. D. (1994). Principles of language learning and teaching (3rd. Ed.). Englewood Cliffs, New Jersey: Prentice Hall Regents.

Brown, H. D. (1993). Principles of language learning and teaching. Indiana: Prentice Hall.

Carroll, S., \& Swain, M. (1993). Explicit and implicit negative feedback: An empirical study of the learning of linguistic generalizations. Studies in Second Language Acquisition, 15, 357-386. http://dx.doi.org/10.1017/S0272263100012158

Chapelle, C. A., \& Abraham, R. G. (1990). Cloze method: What difference does it make? Language Testing, 7, 121-146. http://dx.doi.org/10.1177/026553229000700201

Chapelle, C., \& Green, P. (1992). Field independence/dependence in second-language acquisition research.Language Learning, 42(1), 47-83. http://dx.doi.org/10.1111/j.1467-1770.1992.tb00700.x

de Bot, K. (1996). The psycholinguistics of the output hypothesis. Language Learning, 46, 529-555. http://dx.doi.org/10.1111/j.1467-1770.1996.tb01246.x

Doughty, C. J., \& Williams, J. (1998). Pedagogical choices in focus on form. In C. J. Doughty \& J. Williams (Eds.), Focus on form classroom second language acquisition (pp. 197-262). New York: Cambridge University Press.

Egi, T. (2007).Recasts, learners' interpretation and L2 development. In A. Mackey (Ed.), Conversational interaction in second language acquisition: A collection of empirical studies (pp. 249-267). Oxford: Oxford University Press.

Ellis, R. (2009). A typology of written corrective feedback types. English Language Teaching Journal, 63(2), 97-103.http://dx.doi.org/10.1093/elt/ccn023

Ellis, R. (2007). The differential effect of corrective feedback on two grammatical structures. In A. Mackey (Ed.), Conversational interaction in second language acquisition: A collection of empirical studies (pp. 339-360). Oxford: Oxford University Press. PMid: 17869983

Ellis, R., Loewen, S., \& Erlam, R. (2006).Implicit and explicit corrective feedback and the acquisition of the L2 grammar. Studies in Second Language Acquisition, 28, 339-368. http://dx.doi.org/10.1017/S0272263106060141 
Ellis, R., \& Sheen, Y. (2006).Reexamining the role of recasts in second language acquisition.

Studies in Second Language Acquisition, 28, 575-600. http://dx.doi.org/10.1017/S027226310606027X

Larsen-Freeman, D., \& Long, M. H. (1991). An introduction to second language acquisition research. New York: Longman.

Leeman, J. (2003). Recasts and second language development: Beyond negative evidence. Studies in Second Language Acquisition, 25, 37-63.

Lightbown, P. M., Halter, R. H., White, J. L., \& Horst, M. (2002). Comprehension-based learning: The limits of "do it yourself." Canadian Modern Language Review, 58, 427-464. http://dx.doi.org/10.3138/cmlr.58.3.427

Lightbown, P. M., \& Spada, N. (1994).An innovation program for primary ESL in Quebec. TESOL Quarterly, 28, 563-579. http://dx.doi.org/10.2307/3587308

Lightbown, P. M., \& Spada, N. (1990). Focus on form and corrective feedback in communicative language teaching: Effects on second language learning. Studies in Second Language Acquisition, 12, 429-448. http://dx.doi.org/10.1017/S0272263100009517

Long, M. H. (2006). Problems in second language acquisition. Mahwah, NJ: Erlbaum.

Long, M. H., \& Robinson, P. (1998). Focus on form: Theory, research and practice. In C. J. Doughty \& J. Williams (Eds.), Focus on form classroom second language acquisition (pp. 15-41). New York: Cambridge University Press.

Lourdusamy, A. (1994). Perbezaan Gaya KognitifIndividudanImplikasinyaTerhadap Pendidikan. (SiriSyarahanPerlantikan Professor 1995 Bil. 3). [Individual cognitive style differences and implication on education. (The appointment of professor lecture series, 3, 1995)]. Pulau Pinang: University Sains Malaysia.

Lyster, R. (2004). Differential effects of prompts and recasts in form-focused instruction. Studies in Second Language Acquisition, 26, 399-432. http://dx.doi.org/10.1017/S0272263104263021

Lyster, R. (2002). Negotiation in immersion teacher-student interaction.International Journal of Educational Research, 37, 237-253. http://dx.doi.org/10.1016/S0883-0355(03)00003-X

Lyster, R., \& Izquierdo, J. (2009). Prompts versus recasts in dyadic interaction. Language Learning, 59(2), 453-498. http://dx.doi.org/10.1111/j.1467-9922.2009.00512.x

Lyster, R., \& Ranta, L. (1997). Corrective feedback and learner uptake: Negotiation of form in communicative classrooms. Studies in Second language Acquisition, 19, 37-66.

Lyster, R., \& Saito, K. (2010). Oral feedback in classroom SLA: A meta-analysis. Studies in Second Language Acquisition, 32, 265-302. http://dx.doi.org/10.1017/S0272263109990520

Mackey, A., \& Goo, J. (2007). Interaction research in SLA: A meta-analysis and research synthesis. In A. Mackey (Ed.), Conversational interaction in second language acquisition: A 
collection of empirical studies (pp. 407-452). Oxford: Oxford University Press.

Mackey, A., \& Philip, J. (1998). Conversational interaction and second language development: Recasts, responses, and red herrings? Modern Language Journal, 82, 338-356. http://dx.doi.org/10.1111/j.1540-4781.1998.tb01211.x

Mayer, R. E. (2001). Multimedia learning. United Kingdom: Cambridge University Press. http://dx.doi.org/10.1017/CBO9781139164603

Musser, T. (1998). Individual Differences: How field dependence-independence affects learners, from: http://www.personal.psu.edu/staff/t/x/txm4/paper1.html

Nicholas, H., Lightbown, P. M., \& Spada, N. (2001).Recasts as feedback to language learners. Language Learning, 51, 719-758. http://dx.doi.org/10.1111/0023-8333.00172

Oh, E., \& Lim, D. D. (2005). Cross relationships between cognitive styles and learner variables in online learning environment. Journal of Interactive Online Learning, 4(1).

Ortega, L. (2009). Understanding second language acquisition. London: Hodder Education.

Raven, M. R., Cano, J., Garton, B. L., \& Shelhamer, V. (1993). A comparison of learning styles, teaching styles, and personality styles of pre-service Montana and Ohio agriculture teachers. Journal of Agricultural Education, 31(1), 40-50.

Russell, J., \& Spada, N. (2006). The effectiveness of corrective feedback for second language acquisition: A meta-analysis of the research. In J. Norris \& L. Ortega (Eds.), Synthesizing research on language learning and teaching (pp. 133-164). Amsterdam: Benjamins. PMCid:1621066

Schmidt, R. (1990). The role of consciousness in second language learning. Applied Linguistics, 11, 129-158. http://dx.doi.org/10.1093/applin/11.2.129

Sheen, Y. (2007). The effects of corrective feedback, language aptitude, and learner attitudes on the acquisition of English articles. In A. Mackey (Ed.), Conversational interaction in second language acquisition: A collection of empirical studies (pp. 301-322). Oxford: Oxford University Press.

Sheen, Y. (2006). Exploring the relationship between characteristics of recasts and learner uptake. Language Teaching Research, 10, 361-392. http://dx.doi.org/10.1191/13621688061r203oa

Sheen, Y. (2004). Corrective feedback and learner uptake in communicative classrooms across instructional settings. Language Teaching Research, 8, 263-300. http://dx.doi.org/10.1191/13621688041r146oa

Stansfield, C., \& Hansen, J. (1983). Field dependence-independence as a variable in second language cloze test performance. TESOL Quarterly, 17(1), 29-38. http://dx.doi.org/10.2307/3586422

Stern, H. H. (1983). Fundamental concept of language teaching. Oxford University Press. 
Summerville, J. (1999). The role of awareness of cognitive style in hypermedia. International Journal of Educational Technology, 1(1).

Tinajero, C., \& Páramo, M. F. (1998). Field dependence-independence in second-language acquisition: Some forgotten aspects. The Spanish Journal of Psychology, 1(1), 32-38.

Town, D. A. (2003).Cognitive Style and Learning Strategies. Retrieved from http://www. monografias.com/trabajos16/learning-styles.shtml styles/learning

Truell, A. D. (2001). Student attitudes toward evaluation. The Delta Phi Epsilon Journal, $43(1), 40-49$.

Truscott, J. (1996). The case against grammar correction in L2 writing classes. Language Learning, 46, 327-369. http://dx.doi.org/10.1111/j.1467-1770.1996.tb01238.x

Yang, Y., \& Lyster, R. (2010).Effects of form-focused practice and feedback on Chinese EFL learners' acquisition of regular and irregular past tense forms. Studies in Second Language Acquisition, 32, 235-263. http://dx.doi.org/10.1017/S0272263109990519

Wang, X. C., Hinn, D. M., \& Kanfer, A. G. (2001). Potential of computer supported collaborative learning for learners with different learning styles. Journal of Research on Technology in Education, 34(1), 75-85.

Witkin, H. A., Moore, C. A., Goodenough, D. R., \& Cox, R. W. (1977).Field independent and field dependent cognitive styles and their educational implications. Review of Educational Research, 47, 1-64.

Witkin, H. A., Oltman, P. K., Raskin, E., \& Karp, S. A. (1971). Group embedded figures test manual. Consulting Psychologist Press, Inc. Palo Alto, CA.

\section{Copyright Disclaimer}

Copyright reserved by the author(s).

This article is an open-access article distributed under the terms and conditions of the Creative Commons Attribution license (http://creativecommons.org/licenses/by/3.0/). 